NOTAS

\title{
EL RENACIMIENTO DE SICILIA ESTUDIO INTRODUCTORIO
}

María Teresa Martínez*

¡Bandoleros, policía, Estado, son todos uno, como el Padre, el Hijo y el Espíritu Santo!

Pisciotta (asesino de Salvatore Giuliano)

En 1972 el director de cine estadounidense Francis Ford Coppola, adaptó el guión de la novela original de Mario Puzo, El Padrino. Con ello no sólo marcaría un estilo cinematográfico, sino además edificaría la imagen predominante que sobre la mafia se tiene.

Aunque la descripción icónica de Coppola se concentra en la Cosa Nostra norteamericana, evoca una tradición siciliana que se presiente irreductible. Pero en Sicilia, no sólo hay ‘Corleones’ y ‘Sollozos, ${ }^{1}$ hacérse-

* Pasante de la licenciatura en Ciencias Políticas, UNAM.

${ }^{1}$ Vito Corleone y Sollozo son dos de los personajes principales de la historia de Puzo. lo saber al mundo y creerlo, ha sido la titánica labor de un grupo de sicilianos, de entre los que sobrevive Leoluca Orlando. Al frente de un proyecto de reestructuración institucional y sobre todo cultural de su país, Orlando promueve mundialmente un programa de legalidad que no se basa en normas, prohibiciones y persecuciones, sino en convicciones de la sociedad.

El presente estudio, pretende ser una revisión de los antecedentes del esfuerzo de Leoluca Orlando, y con ello dimensionar adecuadamente sus alcances, así como encontrarnos en los vicios y en las posibilidades del inconcluso esfuerzo de los sicilianos. 
En la historia moderna, pocos sucesos son tan impactantes como la Segunda guerra mundial. Un fenómeno como éste, se vive dolorosamente en cada uno de sus días, pero se padece aún más después. Las consecuencias de este conflicto bélico, son inconmensurables, porque el mundo se dividió radicalmente en 'rojos' y 'azules', y porque un escenario de guerra latente, silenciosa y constante se alojó en todas partes como Guerra fría. A partir de ella, las grandes potencias capitalizaban su poder una y otra vez, a despecho de las minúsculas naciones cuyo destino dependía del desencuentro de izquierda y derecha.

Italia, uno de los países que más perdieron en la Guerra, no sólo sufrió una destrucción física, producto de los bombardeos de las tropas aliadas, donde las escaleras derruidas de sus majestuosas construcciones ya no llevan a ningún lado, un sin sentido como el del andamiaje institucional, en el que la sociedad supuso estar parada.

Por hartazgo o miedo, el anticomunismo fue cobrando un sitio preponderante en todas sus provincias. Pronto se convirtió en un sentimiento violentado por los norteamericanos y consecuentado por la que sería la nueva clase política italiana. El Partido Demócrata Cristiano (DC) encontró en ello, materia suficiente para justificar su razón de ser y fortalecerse a partir de cualquier tipo de alianzas.

El mejor testigo de esta peligrosa disposición es Sicilia, una de las tres islas del territorio italiano, ${ }^{2}$ una región cuyo simbolismo no radica en ser la isla más grande del mar Mediterráneo, ni en poseer el único volcán activo de Europa, el Etna. Lo que el mundo sabe de esta isla, es lo que su propia ciudad capital, Palermo, constató por décadas. Sólo se conciben historias de sangre y venganzas, sólo se imagina un poblador, la mafia.

En Sicilia, el anticomunismo y un frustrado movimiento separatista, desembocaron en la fortaleza de los bandoleros, pero, sobre todo, en la irrupción por todo lo alto de los 'amigos ${ }^{33}$ de Italia, la mafia. La democracia cristiana aceptó aliarse con la Cosa Nostra, una organización mafiosa cuyo poder emanaba del tráfico de alcohol y drogas, se disimulaba en la industria constructora y se revitalizó con la oportunidad de hacer y ser la política italiana.

Los 50 son conocidos como años de saqueo, durante los cuales Estados Unidos liberó de prisión a Lucky Luciano -distinguido miembro de la Cosa Nostra norteamericana-, para

${ }^{2}$ Las otras dos son Capri y Cerdeña. ${ }^{3}$ Así solía referirse a la mafia, tanto entre sus miembros como entre la sociedad. 
NOTAS

repatriarlo a Italia y con ello asegurar que la mafia estuviera a su favor en la lucha contra el comunismo galopante. Entonces, aparecieron ciertos nombres cuyo peso es claro en la lógica gubernamental en lo público y en la mafia siciliana en lo privado. Tal es el caso de Giulio Andreotti, ${ }^{4}$ un importante personaje político no sólo en la isla, sino en muchas otras provincias. En la arena sindical, en la parlamentaria o desde cualquier otro lugar, Andreotti representaba la nueva realidad del lugar: la clase política y la mafia eran 'amigos'. Detrás de intereses semejantes hubo otras formas de poder privilegiando estos acuerdos; el clero, por ejemplo, pronto entendió la dinámica y se ajustó a ella.

La mafia, trascendió el mercado de la droga y se instaló en los referentes culturales de la región italiana. Los 'amigos' eran parte de una cotidianidad en la que la complicidad del silencio se volvió obvia. El centro de la ciudad de Palermo fue económicamente saqueado, se fue vaciando la grandeza de sus mercados y el barullo de sus calles, hasta volverse casi desértico. En cambio, se invertirá en el desarrollo urbano

${ }^{4}$ Andreotti fue senador vitalicio, miembro de la Democracia cristiana, ministro una veintena de veces en distintas provincias y primer ministro siete veces hasta 1992. de la periferia. La población se fue a vivir a sus nuevas y atractivas casas, todas, obra material e intelectual de la mafia.

Con el tiempo, la Cosa Nostra comprendió que su éxito, como el de cualquier empresa, estaba en su capacidad de transformarse, de manera que se hizo urbana y multinacional, extendiendo sus fronteras para definir la economía de Italia e influir seriamente en la del resto de Europa.

La mafia influía en todos los espacios de los sicilianos, dentro y fuera de la isla, en lo cotidiano y en lo excepcional. El arte y la religión, las escuelas y los espacios recreativos, todo se construía desde la mafia o por su mano, de modo que nadie vivía al margen de la misma.

Los democratacristianos se educaron con los líderes de la Cosa Nostra, compartieron la infancia y la juventud con todas sus implicaciones, se conocían bien entre sí y podían entenderse. El desenvolvimiento paralelo de personajes políticos y capos sicilianos, explica en gran medida el inicio de un proyecto antimafia de consecuencias radicales.

Es difícil determinar el momento preciso en el que naciera el esfuerzo antimafia. Se sabe que a finales de los 70 el principal partido político -el DC- experimentó algunas frac- 
turas. Por un lado había personajes como Cesare Terranova y Giovanni Falcone, que desde el Parlamento italiano o alguna fiscalía, comenzaron a promover un proyecto antimafia que comprometía a otros políticos, magnates y banqueros. Frente a ellos estaba un ala mucho más conservadora del partido, cuyo líder era el longevo y reconocido Andreotti. La división del partido se radicalizó con el secuestro y posterior asesinato del entonces Primer Ministro Aldo Moro. Al frente de la DC, Moro fortaleció a Andreotti en las urnas, pero también fue el ideólogo del acuerdo que la DC sostuvo con el Partido Comunista Italiano (PCI). Semejante osadía provocó que las Brigadas Rojas ${ }^{5}$ acabaran con su vida en mayo 1978 , una pérdida conveniente para los conservadores y muy poco afortunada para quienes intentaban instrumentar un movimiento antimafia.

Aunque tal suceso cobró importancia en la opinión pública internacional, no alcanzó mayores efectos que el pronunciamiento público del Papa Pablo VI. ${ }^{6}$

En 1979, Terranova -entonces Fiscal General de Palermo- fue asesinado, sumando su muerte a la del

\footnotetext{
${ }^{5}$ Grupo izquierdista radical.

${ }^{6}$ Carta a las Brigadas Rojas en relación al secuestro de Aldo Moro, 22 de abril de 1978.
}

periodista Mino Pecorelli y a otras tantas que más tarde se vincularían con la mafia.

Italia llegó a la década de los 80 en un ambiente de mayor hostilidad, y, no obstante el riesgo, Falcone siguió con la pretensión de transformar la estructura jurídica de su país, evitando con ello que el estado de derecho se definiera desde los intereses de la mafia.

Con ayuda de algunos informantes estratégicos, ${ }^{7}$ Falcone comenzó a entender las entrañas de la mafia y a debilitar algunos procedimientos de la organización que no tenía reparo alguno en deshacerse de periodistas, diplomáticos, intelectuales o de cualquiera que indagara de más sobre su quehacer. Para entonces, Salvatore Riina, cabeza de la Cosa Nostra, había solidificado sus relaciones con la clase política y en particular con Salvo Lima, ${ }^{8}$ quien no sólo era parte medular de las filas del PDC, sino miembro de la Cosa Nostra. Por si fuera poco, había banqueros -Michele Sindona-y magnates-Nino

\footnotetext{
${ }^{7}$ Mafiosos menores marginados por la cúpula de la Cosa Nostra.

${ }^{8}$ Lima fue Alcalde de Palermo, Ministro del Gobierno y miembro del Parlamento Europeo. Líder de la rama de Andreotti en la DC siciliana y asesinado en 1992.
} 
NOTAS

e Ignazio Salvo- ${ }^{9}$ favoreciendo a Riina y a los suyos.

Los cambios que instrumentó el magistrado Falcone tuvieron una consecuencia que incomodó especialmente a la mafia y al propio aparato gubernamental, pues en 1985 comenzó el Gran Juicio, a partir del cual personajes como Andreotti, Ignazio Salvo, ${ }^{10}$ Claudio Vitalone ${ }^{11}$ y Nino Salvo ${ }^{12}$ serían procesados por malversación de fondos públicos y, en particular, por sus presuntos nexos con la mafia.

Giovanni Falcone no estaba solo en tal empresa, tenía colaboradores cercanos como Paolo Borselino, Fiscal General de Palermo. La ofensa de ambos magistrados a la mafia era muy clara, y a ésta se adhirió el agravio político de Leoluca Orlando, entonces alcalde de Palermo, con sus constantes pronunciamientos en contra de la mafia.

\footnotetext{
${ }^{9}$ Ambos miembros de la Democracia Cristiana.

${ }^{10}$ Arrestado en 1984 y sentenciado más tarde. Asesinado en 1992.

${ }^{11}$ Vitalone había sido magistrado en Roma, Senador y ministro, miembro de la DC. Fue juzgado, acusado de organizar el asesinato de Pecorelli, por supuestas órdenes de Andreotti.

${ }^{12}$ Aunque fue arrestado en 1984, un tumor cerebral le impidió enfrentar el ‘Gran Juicio’, falleció en 1986.
}

No sorprendió a nadie que Riina los amenazara de muerte. Las advertencias contra los magistrados fueron cumplidas. Pero sus asesinatos no fueron como cualquier atentado 'aleccionador' de la mafia, fueron ejecuciones más violentas y donde perdieron la vida no sólo los magistrados. Con Giovanni Falcone ${ }^{13}$ murió también su esposa y tres de sus escoltas -el 23 de mayo de 1992-al explotar un tubo de desagüe de la autopista a Palermo por la que transitaban. Borselino, que tras la muerte de Falcone sabía que la suya era inminente, se dedicó a esclarecer el asesinato de Falcone, pero apenas un mes después -el 19 de julio de 1992se consumó su asesinato cuando al tocar el timbre del edificio de su madre, estalló un coche bomba, acabando con su vida, la de sus guardaespaldas y destruyendo parte del edificio.

La mafia fracturó el intento adversario que se construía desde el marco jurídico, parecía como si tras de eso, no quedara mucho más que hacer, sino esperar la muerte de Leoluca Orlando. Sin embargo, la sociedad no tomó estos asesinatos con la misma perplejidad que los anteriores, tal vez por el grado de agresividad o, probablemente, porque también la indiferencia tiene un límite.

${ }^{13}$ Quien había sido transferido al Ministerio de Justicia en Roma en 1991. 
Tal como lo detalla Leoluca Orlando, las madres de familia acudieron a verlo, poniendo a sus propios hijos de por medio para salvaguardar la vida del alcalde. La sociedad civil, que hasta entonces había participado con su silencio, decidió sumarse al malherido esfuerzo antimafia. Con ello se fortalece La Red (La Rete), organismo creado en 1991, que con pretensiones de partido político abandera un movimiento de legalidad en Sicilia. Además, Orlando rompe con la Democracia Cristiana.

Hoy en día, Leoluca Orlando es un político respetado en toda Europa, pues aunque no cuenta con suficientes recursos monetarios para acabar rotundamente con la mafia, tiene a la sociedad civil de su lado. La mafia, por su parte, sobrevive sólo con el dinero y apoyo de ciertos políticos.

A decir del propio Leoluca, la caída del Muro de Berlín, el derrumbe de la URSS y el colapso del comunismo disminuyeron el interés que Estados Unidos tenía sobre la vida política italiana. Sólo por eso se explica que el esfuerzo de Falcone y Borselino haya materializado un juicio contra Andreotti ${ }^{14}$ y otros polí-

\footnotetext{
${ }^{14}$ Andreotti fue absuelto en 1999 y actualmente es director de la influyente publicación católica de tiraje internacional 30 Giorni.
}

ticos, sólo así es posible que el esfuerzo antimafia conocido como 'el carro siciliano’ haya tenido dos magistrados edificando la rueda 'institucional' para que, con el tiempo, Orlando pudiera erigir su empresa por la cultura de la legalidad.

Sin embargo, el esfuerzo transformador de Orlando y de la sociedad civil organizada en torno al Instituto Renacimiento Siciliano, tiene el reto de resolver la paradoja que enfrenta la transformación de una sociedad capaz de creer en la cultura de la legalidad y que, al mismo tiempo, tiene como Primer ministro a un personaje ampliamente relacionado con la Cosa Nostra. Silvio Berlusconi, no ha sido enjuiciado por sus nexos con la mafia, pero es de todos sabido que existen. También se sabe que tras la aprehensión de Riina -once meses después del asesinato de Borselino- ${ }^{15}$ Giovanni Brusca, su sucesor al frente de la Cosa Nostra, estuvo detrás del actual Primer ministro en su triunfo electoral en Sicilia en 1995, cuando en el resto del país ganó la izquierda moderada. 